\title{
Distributional aspects of the quality change bias in the CPI: evidence from Spain
}

\author{
Javier Ruiz-Castillo ${ }^{a}$, Eduardo Ley ${ }^{\mathrm{b}, *}$, Mario Izquierdo ${ }^{\mathrm{c}}$ \\ ${ }^{\mathrm{a}}$ Economics Department, Universidad Carlos III de Madrid, Madrid, Spain \\ ${ }^{\mathrm{b}}$ International Monetary Fund Institute, 700 19th St. NW, Washington, DC 20431, USA \\ ${ }^{\mathrm{C}}$ FEDEA and Bank of Spain, Madrid, Spain
}

\begin{abstract}
This paper shows that the richer households are significantly more affected by the quality-change bias (QCB) in the CPI. The empirical analysis combines the detailed information pertaining to the size of the QCB for the US with household-specific CPIs for Spain. (c) 2002 Elsevier Science B.V. All rights reserved.
\end{abstract}

Keywords: Plutocratic gap; Money inequality; Price index; CPI; Quality bias

\section{Introduction}

Quality change (including new products) poses considerable problems to agencies responsible for elaborating the CPI in every country. The Boskin et al. (1996) Senate commission concluded that the CPI in the US overstates the true inflation by $0.61 \%$ a year due to a failure on the part of the BLS (Bureau of Labor Statistics) to take fully into account the quality changes experienced in many sectors of the economy and to consider in a timely fashion the value of newly available goods to consumers.

This paper assesses the conjecture raised by some critics of the Boskin commission's report that new products and goods influenced by quality effects are disproportionately consumed by the rich-see, e.g., Deaton (1998), and Madrick (1997). Moreover, the distributional consequences of eliminating the QCB are examined by the QCB impact on two scalars: (1) the CPI plutocratic gap, and (2) the change in money inequality.

In order to study the distributional implications of the QCB, a set of household-specific CPIs is

${ }^{*}$ Corresponding author. Tel.: + 1-202-623-6107; fax: +1-202-589-6107.

E-mail address: eley@imf.org (E. Ley). 
needed. Such information is not readily available for the US economy. However, for the Spanish case it is possible to construct Laspeyres price indexes for all households interviewed in the three latest budget household surveys (1973-1974, 1980-1981, and 1990-1991). In this paper it is assumed that the structure of the QCB provided by the Boskin commission-appropriately modified after a careful reading of the arguments advanced by its critics in the BLS, and further adjusted to the peculiarities of the Spanish economy-can be reasonably applied to Spain.

\section{The quality-change bias in the US and Spanish economies}

The CPI can be written as the weighted average of goods price ratios: $\mathrm{CPI}_{t}=\Sigma_{i} W_{i}\left(p_{i t} / p_{i 0}\right)$, where $W_{i}$ is the aggregate share of the expenditure on good $i$ in total expenditure. Assume that quality change has not been completely eliminated from the price ratios $\left(p_{i t} / p_{i 0}\right)$, and let $b_{i}$ be the best estimate of the QCB in the measurement of inflation of good $i$ expressed in percent per year. Then the QCB for the economy as a whole is given by QCB $=\Sigma_{i} W_{i} b_{i}$. Column 1 of Table 1 presents the weights $W_{i}$ of the 27 categories (used by the Boskin Commission) in the US CPI in December 1995, column 2 lists the commission estimates of the QCB in each case. Moulton and Moses (1997) contains detailed and convincing criticisms of the Boskin commission estimates. In particular, they point out that in nine categories $(1,2,3,8,10,14,20,25$, and 27), in the absence of evidence, the commission is forced to fall back simply on their best judgement. This group accounts for 0.11 percentage points of the total QCB. Following these arguments, the QCB of motor fuel (category 20) is reduced to 0.15 , and those of the remaining categories in this group are reduced by one-half. Column 3 lists the QCB estimates after these corrections. Columns 4 to 6 contain the aggregate weights, $W_{i}$, for the Spanish economy.

It could be argued that the dynamic nature of the US economy is characterized by more quality changes and the appearance of new products than what we should expect in the Spanish economy. However, the Spanish statistical agency is much less active than the BLS in eliminating quality change from price variation. Therefore, in this paper it is assumed that, as a first approximation, the structure of the QCB for the US (Table 1, column 3) can be applied to the Spanish economy. The advantage of accepting this assumption is twofold: (i) we can study how our estimates of the QCB in Spain are affected by changes over time in the aggregate weights, and (ii) we can assess whether the QCB is more pronounced for the rich or the poor Spanish households in different moments in time.

In order to compare the structure of the QCB in the US and the Spanish economies, it is advisable to reduce the dimensionality of the commodity space. Column 1 of Table 2 presents the contribution of each of seven large expenditure groups to the overall QCB in the US. Column 2 provides the same information for the US, but for the corrected QCB structure which is applied to Spain. Columns 3 to 5 provide the contribution of the seven groups to the overall QCB in Spain in 1990-1991, 1980-1981, and 1973-1974, respectively.

The total QCB in the US economy in 1995 was initially estimated at $0.61 \%$ per year. When the weight of household appliances is modified from $2.13 \%$ to the lower weight of $0.806 \%$ so that weights add to 1 (see note $a$ in Table 2 of Boskin et al., 1996) the QCB becomes $0.58 \%$ per year. If the corrections included in column 3 of Table 1 are accepted for the US, then the QCB is further reduced to $0.55 \%$ per year. In comparison, the QCB in Spain in 1990-1991 is estimated to be $0.41 \%$ per year. Since the QCB for all expenditure categories has been taken to be the same in the two countries, the 
Table 1

The quality change bias in the US, and the US vs. Spanish aggregate weight structure in percentage terms

\begin{tabular}{|c|c|c|c|c|c|c|}
\hline & \multirow{2}{*}{$\begin{array}{l}\text { US CPI } \\
\text { weights }\end{array}$} & \multicolumn{2}{|l|}{ US QCB } & \multicolumn{3}{|c|}{ Spanish CPI weights } \\
\hline & & Original & Corrected & $1990-1991$ & $1980-1981$ & $1973-1974$ \\
\hline \multicolumn{7}{|l|}{ I. Food, beverages and tobacco } \\
\hline 1. Food at home & 8.54 & 0.30 & 0.15 & 20.73 & 26.23 & 31.87 \\
\hline 2. Fresh fruits and vegetables & 1.34 & 0.60 & 0.30 & 3.02 & 3.80 & 4.01 \\
\hline 3. Alcoholic beverages & 1.57 & 0.15 & 0.075 & 0.93 & 1.44 & 2.11 \\
\hline 4. Tobacco & 1.61 & 0.00 & 0.00 & 1.51 & 1.17 & 1.52 \\
\hline \multicolumn{7}{|l|}{ II. Apparel and shoes } \\
\hline 5. Apparel and shoes & 5.52 & 1.00 & 1.00 & 9.66 & 8.67 & 7.70 \\
\hline \multicolumn{7}{|l|}{ III. Housing } \\
\hline 6. Shelter & 28.29 & 0.25 & 0.25 & 19.83 & 16.14 & 12.01 \\
\hline 7. Fuels & 3.79 & 0.00 & 0.00 & 2.76 & 1.51 & 1.47 \\
\hline 8. Other utilities, incl. telephone & 3.22 & 1.00 & 0.50 & 1.63 & 2.52 & 2.05 \\
\hline \multicolumn{7}{|l|}{ IV. Household equip. and serv. } \\
\hline 9. Appliances & 2.13 & 3.60 & 3.60 & 0.97 & 1.28 & 0.89 \\
\hline 10. House furnishings & 2.64 & 0.30 & 0.15 & 1.82 & 2.14 & 2.68 \\
\hline 11. Housekeeping supplies & 1.12 & 0.00 & 0.00 & 1.97 & 3.34 & 3.40 \\
\hline 12. Housekeeping services & 1.48 & 0.00 & 0.00 & 0.91 & 0.89 & 1.15 \\
\hline \multicolumn{7}{|l|}{ V. Medical care } \\
\hline 13. Prescription drugs & 0.89 & 2.00 & 2.00 & 0.49 & 0.66 & 1.20 \\
\hline 14. Non prescription drugs and medical supplies & 0.39 & 1.00 & 0.5 & 0.56 & 0.33 & 0.08 \\
\hline 15. Professional medical services & 3.47 & 3.00 & 3.00 & 1.17 & 0.99 & 0.43 \\
\hline 16. Hospital services & 2.26 & 3.00 & 3.00 & 0.11 & 0.09 & 0.50 \\
\hline 17. Health insurance & 0.36 & 0.00 & 0.00 & 0.29 & 0.33 & 0.44 \\
\hline \multicolumn{7}{|l|}{ VI. Transportation } \\
\hline 18. New vehicles & 5.03 & 0.59 & 0.59 & 4.09 & 3.33 & 2.42 \\
\hline 19. Used vehicles & 1.34 & 1.59 & 1.59 & 0.00 & 0.00 & 0.00 \\
\hline 20. Motor fuel & 2.91 & 0.25 & 0.15 & 3.43 & 4.13 & 2.51 \\
\hline 21. Other private transportation & 6.15 & 0.00 & 0.00 & 4.05 & 4.11 & 1.99 \\
\hline 22. Public transportation & 1.52 & 0.00 & 0.00 & 1.12 & 1.40 & 1.89 \\
\hline \multicolumn{7}{|l|}{ VII and VIII. Other goods and services } \\
\hline 23. Commodities & 1.98 & 2.00 & 2.00 & 3.21 & 2.28 & 1.78 \\
\hline 24. Services & 2.39 & 0.00 & 0.00 & 2.34 & 2.89 & 5.37 \\
\hline 25. Food away & 5.89 & 0.30 & 0.15 & 8.76 & 5.85 & 6.16 \\
\hline 26. Personal care & 1.17 & 0.90 & 0.90 & 1.80 & 1.68 & 2.13 \\
\hline 27. Personal and educational expenses & 4.34 & 0.20 & 0.10 & 2.83 & 2.79 & 2.24 \\
\hline Total & 100 & 0.61 & 0.55 & 100 & 100 & 100 \\
\hline
\end{tabular}

differences between columns 2 (US) and 3 (Spain) in Table 2 are exclusively due to the differences in aggregate weights. The contribution to the overall QCB by expenditure groups I, II and VII is larger in Spain. Given the much smaller role of the public health system in the US, relative to a country like Spain where most of the health expenditures correspond to the public sector, the contribution of group $\mathrm{V}$ to the QCB is larger in the US by 0.14 percentage points per year. This, together with the 0.10 
Table 2

The quality-change bias in the US and Spain

\begin{tabular}{|c|c|c|c|c|c|c|}
\hline & & \multicolumn{2}{|l|}{ US bias } & \multicolumn{3}{|c|}{ Corrected Spanish bias } \\
\hline & & Original & Corrected & $1990-1991$ & $1980-1981$ & $1973-1974$ \\
\hline I & Food, beverages and tobacco & 0.04 & 0.02 & 0.04 & 0.05 & 0.06 \\
\hline II & Apparel and shoes & 0.06 & 0.06 & 0.10 & 0.09 & 0.08 \\
\hline III & Housing & 0.10 & 0.09 & 0.06 & 0.05 & 0.04 \\
\hline IV & Household equipment and services & 0.08 & 0.08 & 0.04 & 0.05 & 0.04 \\
\hline V & Medical care & 0.19 & 0.19 & 0.05 & 0.05 & 0.05 \\
\hline VI & Transportation & 0.06 & 0.06 & 0.03 & 0.03 & 0.02 \\
\hline \multirow[t]{2}{*}{ VII } & Other goods and services & 0.08 & 0.06 & 0.10 & 0.07 & 0.07 \\
\hline & Aggregate Bias & 0.61 & 0.55 & 0.41 & 0.39 & 0.35 \\
\hline
\end{tabular}

percentage points attributable to the remaining groups III, IV, and VI, explains the difference between the US QCB and the Spanish one. On the other hand, the relative importance of 'apparel' and 'other goods and services' (groups II and VII) and, above all, of 'housing' (group III), is monotonically decreasing in Spain as we delve further into the past. Except for food, beverages and tobacco (group I), which consists mainly of necessities and whose weight declines as household total expenditures increase over time in real terms, the remaining groups IV, V, and VI have weights which remain essentially constant over time. Consequently, the QCB, in percent per year, increases from 0.35 in $1973-1974$, to 0.39 in $1980-1981$ and 0.41 in $1990-1991$.'

Finally, Table 3 presents the QCB by decile of the total household expenditures distribution. As

Table 3

The QCB by decile of the household total expenditures distribution

\begin{tabular}{llll}
\hline Decile & \multicolumn{3}{l}{ Quality-change bias } \\
\cline { 2 - 4 } & QI 91-Jan 98 & QI 81-QI 91 & 73/74-QI 81 \\
\hline 1 & 0.310 & 0.308 & 0.277 \\
2 & 0.346 & 0.340 & 0.307 \\
3 & 0.361 & 0.361 & 0.319 \\
4 & 0.374 & 0.363 & 0.323 \\
5 & 0.393 & 0.382 & 0.328 \\
6 & 0.403 & 0.374 & 0.335 \\
7 & 0.410 & 0.388 & 0.342 \\
8 & 0.417 & 0.397 & 0.339 \\
9 & 0.428 & 0.401 & 0.349 \\
10 & 0.446 & 0.399 & 0.345 \\
Total & 0.409 & 0.386 & 0.346 \\
\hline
\end{tabular}

Percentage points per year.

\footnotetext{
${ }^{1}$ Assuming the uncorrected Boskin commission QCB structure in column 2 of Table 1, the bias in the Spanish case would be raised to $0.48,0.47$, and $0.44 \%$ per year in 1990-1991, 1980-1981, and 1973-1974, respectively, in comparison with $0.61 \%$ per year in the US.
} 
conjectured, richer households are significantly more affected by the QCB-e.g. the QCB for the top decile is between 25 and $45 \%$ larger than for the bottom decile, depending on the household survey.

\section{Distributional aspects of eliminating the QCB in the Spanish economy}

\subsection{Effects on the plutocratic gap}

The official CPI can also be expressed as a weighted average of the household-specific CPIs with weights proportional to household total expenditures. Because the rich households weight more than the poor households, the CPI has been called a plutocratic price index (Prais, 1958). Let us define the household-specific quality change bias by $b^{h}=\Sigma_{i} w_{i}^{h} b_{i}$. Then we have that the QCB for the economy as a whole is the plutocratic weighted average of the household-specific quality biases.

In Izquierdo et al. (2002) the plutocratic gap (PG) is defined as the difference in the measurement of inflation when the plutocratic CPI is used rather than a (democratic) group price index in which all households have the same weight. The PG is positive or negative according to whether prices behave relatively more in an anti-rich or anti-poor manner, respectively. The individual price index after the correction for the QCB is simply $c p i_{t}^{h}\left(1-b^{h}\right)$. Thus, whether new products and goods affected by quality effects are disproportionately consumed by the rich households can be ascertained by whether or not the PG magnitude declines after the elimination of the QCB.

Household-specific price indexes are constructed using the last three Spanish household surveys, and the PG is estimated for Winter 1991-January 1998, Winter 1981-Winter 1991, and 1973/74Winter 1981. The results, reported in Izquierdo et al. (2002), are that the overall PG in these three periods was equal to $0.055,0.091$, and $0.265 \%$ per year, respectively. This means that in all three periods the inflation experienced by the richer households has been relatively greater than the one experienced by the poorer households. Thus, prices have behaved, with different intensities, in an anti-rich way.

As Table 4 shows, when the PG is computed in the three periods in terms of the indexes in which the QCB has been eliminated, it is equal to $0.035,0.073$ and $0.249 \%$ per year, respectively. This means that $36.4,19.8$ and $6.0 \%$ of the PG could be attributed to the QCB. Thus, in the three cases the conjecture that this phenomenon is more prevalent among the rich households appears to be supported by the facts. Furthermore, the fact that the further we move into the past the smaller is the decline in

Table 4

The plutocratic gap in Spain: before and after the correction for the quality-change bias

\begin{tabular}{lccc}
\hline & \multicolumn{3}{c}{ Plutocratic gap } \\
\cline { 2 - 4 } & QI 91-Jan 98 & QI 81-QI 91 & 73/74-QI 81 \\
\hline Before correcting for the QCB & 0.055 & 0.091 & 0.265 \\
After correcting for the QCB & 0.035 & 0.073 & 0.249 \\
Change & $-36.36 \%$ & $-19.78 \%$ & $-6.04 \%$ \\
\hline
\end{tabular}

The plutocratic gap is expressed in percentage points per year. 
the PG as a result of the elimination of the QCB, is consistent with the fact that household total expenditures in real terms decline as well when moving in that direction.

\subsection{The effect on the change in income inequality}

Consider the household income or expenditures distributions in two different time periods, $\mathbf{x}_{1}=\left(x_{1}^{1}, \ldots, x_{1}^{H}\right)$ and $\mathbf{x}_{2}=\left(x_{2}^{1}, \ldots, x_{2}^{H^{\prime}}\right)$, where $x_{t}^{h}$ represents household $h$ 's total expenditures in period $t$. Let $\mathbf{p}_{1}$ and $\mathbf{p}_{2}$ be the price vectors in the two situations. Household $h$ total expenditures in situation 1 can be expressed at prices $\mathbf{p}_{2}, x_{1,2}^{h}$, by multiplying her original money income in period 1 , $x_{1}^{h}$, by a statistical price index of the Laspeyres type: $x_{1,2}^{h}=\mathbf{p}_{1} \cdot \mathbf{q}_{1}^{h}\left(\mathbf{p}_{2} \cdot \mathbf{q}_{1}^{h} / \mathbf{p}_{1} \cdot \mathbf{q}_{1}^{h}\right)=\mathbf{p}_{2} \cdot \mathbf{q}_{1}^{h}$, where $\mathbf{q}_{1}^{h}$ is the bundle consumed by household $h$ in period 1 . Let $\mathscr{I}$ be an inequality index, the change in money income inequality, $\Delta M$, can be expressed as the sum of two terms:

$$
\Delta M=\mathscr{I}\left(\mathbf{x}_{2}\right)-\mathscr{I}\left(\mathbf{x}_{1}\right)=\left[\mathscr{I}\left(\mathbf{x}_{2}\right)-\mathscr{I}\left(\mathbf{x}_{1,2}\right)\right]+\left[\mathscr{I}\left(\mathbf{x}_{1,2}\right)-\mathscr{I}\left(\mathbf{x}_{1}\right)\right]=\Delta R+\Delta P .
$$

The term $\Delta R=\mathscr{I}\left(\mathbf{x}_{2}\right)-\mathscr{I}\left(\mathbf{x}_{1,2}\right)$ is the change in real income inequality while $\Delta P=\mathscr{I}\left(\mathbf{x}_{1,2}\right)-\mathscr{I}\left(\mathbf{x}_{1}\right)$ captures the distributional impact of price changes on inequality measurement according to the first-period households' choices. When price changes are anti-rich and PG is positive (as is the case in Spain during the period considered), the term $\Delta P$ is positive. In this case, if $\Delta R>0$ then $\Delta M$ would indicate a lower decrease in real income inequality; if, however, $\Delta R<0$ then $\Delta M$ would indicate a larger increase in real income inequality. On the other hand, if new products and goods affected by quality effects are disproportionately consumed by the rich households (as the results in the previous subsection suggest), then the term $\Delta P$ should be lower after the elimination of the QCB.

Following Buhmann et al. (1988), let $\mathbf{y}(\theta)$ denote the distribution of equivalent household total expenditures with $y^{h}(\theta)=x^{h}\left(s^{h}\right)^{-\theta}$, and $\theta \in[0,1]$. Denote by $\mu(\mathbf{y}(\theta))$ the mean of the distribution of $\mathbf{y}(\theta)$, define $z^{h}(\theta)=y^{h}(\theta) / \mu(\mathbf{y}(\theta))$, and let $\mathbf{z}(\theta)$ be the corresponding distribution of $z^{h}(\theta)$.

To verify whether the term $\Delta P$ is positive in the three periods, an inequality index of equivalent household expenditures must be computed. Members of the Generalized Entropy family are chosen because they are the only measures of relative inequality that satisfy the usual normative properties and, in addition, are decomposable by population subgroups (Shorrocks, 1984). The Generalized Entropy family can be described by the following convenient cardinalization: $\mathscr{I}_{c}(\mathbf{z}(\theta))=(1-1 / H$ $\left.\sum z^{h}(\theta)^{c}\right) /(c(1-c))$, when $c \neq 0$, 1. For $c=0$, define $\mathscr{I}_{0}(\mathbf{z}(\theta))=1 / H \sum \ln z^{h}(\theta)$, so that the index is the mean logarithmic deviation. For $c=1$, define $\mathscr{I}_{1}(\mathbf{z}(\theta))=1 / H \sum z^{h}(\theta) \ln z^{h}(\theta)$, which is the original Theil index. The parameter $c$ summarizes the sensitivity of $\mathscr{I}_{c}$ in different parts of the household total expenditures distribution: the more positive (negative) $c$ is, the more sensitive $\mathscr{I}_{c}$ is to differences at the top (bottom) of the distribution (Cowell and Kuga, 1981).

Table 5 presents the estimates for $\Delta P_{c}(\theta)$, expressed in percentage terms of $\mathscr{I}\left(\mathrm{x}_{1}\right)$, for different combinations of the parameter values $(c, \theta)$. These estimates have been computed using 1000 Bootstrap stratified (re)samples. Firstly, as expected, $\Delta P_{c}(\theta)$ is positive for all values of $c$ and $\theta$ in the three panels of Table 5. However, in line with the size of the plutocratic gap in the three periods $(0.055,0.091$, and $0.265 \%$ per year, respectively), the distributional impact of the change in relative prices is between 2-5\%, 4-9\%, and 6-14\% in 1991-1998, 1981-1991, and 1973-1981, respectively. Secondly, the correction of the QCB gives rise to a statistically significant decrease in such a 
Table 5

Changes in expenditure inequality before and after the correction by the quality change bias

\begin{tabular}{|c|c|c|c|c|c|c|c|c|}
\hline \multirow[b]{2}{*}{$c=$} & \multicolumn{4}{|c|}{ Before correcting for QCB } & \multicolumn{4}{|c|}{ After correcting for QCB } \\
\hline & -1 & 0 & 1 & 2 & -1 & 0 & 1 & 2 \\
\hline \multicolumn{9}{|c|}{ Percentage change in inequality from 1991 to 1998 after compensating for price changes } \\
\hline$\theta=0$ & $\begin{array}{c}2.43 \\
(0.162)\end{array}$ & $\begin{array}{c}2.06 \\
(0.126)\end{array}$ & $\begin{array}{c}2.36 \\
(0.210)\end{array}$ & $\begin{array}{c}3.15 \\
(0.606)\end{array}$ & $\begin{array}{c}1.60 \\
(0.182)\end{array}$ & $\begin{array}{c}1.49 \\
(0.161)\end{array}$ & $\begin{array}{c}1.86 \\
(0.298)\end{array}$ & $\begin{array}{c}2.48 \\
(0.935)\end{array}$ \\
\hline$\theta=0.5$ & $\begin{array}{c}3.20 \\
(0.169)\end{array}$ & $\begin{array}{c}2.97 \\
(0.151)\end{array}$ & $\begin{array}{c}3.27 \\
(0.251)\end{array}$ & $\begin{array}{c}4.10 \\
(0.673)\end{array}$ & $\begin{array}{c}2.22 \\
(0.192)\end{array}$ & $\begin{array}{c}2.26 \\
(0.191)\end{array}$ & $\begin{array}{l}2.61 \\
(0.346)\end{array}$ & $\begin{array}{c}3.33 \\
(0.999)\end{array}$ \\
\hline$\theta=1$ & $\begin{array}{c}3.30 \\
(0.167)\end{array}$ & $\begin{array}{c}3.24 \\
(0.154)\end{array}$ & $\begin{array}{c}3.68 \\
(0.251)\end{array}$ & $\begin{array}{c}5.02 \\
(0.624)\end{array}$ & $\begin{array}{c}2.43 \\
(0.186)\end{array}$ & $\begin{array}{c}2.60 \\
(0.185)\end{array}$ & $\begin{array}{c}3.16 \\
(0.314)\end{array}$ & $\begin{array}{c}4.48 \\
(0.819)\end{array}$ \\
\hline \multicolumn{9}{|c|}{ Percentage change in inequality from 1981 to 1991 after compensating for price changes } \\
\hline$\theta=0$ & $\begin{array}{c}4.39 \\
(0.167)\end{array}$ & $\begin{array}{c}4.18 \\
(0.135)\end{array}$ & $\begin{array}{c}5.11 \\
(0.196)\end{array}$ & $\begin{array}{c}7.63 \\
(0.408)\end{array}$ & $\begin{array}{c}3.63 \\
(0.188)\end{array}$ & $\begin{array}{c}3.75 \\
(0.157)\end{array}$ & $\begin{array}{c}4.87 \\
(0.236)\end{array}$ & $\begin{array}{c}7.60 \\
(0.506)\end{array}$ \\
\hline$\theta=0.5$ & $\begin{array}{c}4.75 \\
(0.180)\end{array}$ & $\begin{array}{c}4.82 \\
(0.170)\end{array}$ & $\begin{array}{c}5.95 \\
(0.263)\end{array}$ & $\begin{array}{c}8.95 \\
(0.727)\end{array}$ & $\begin{array}{c}3.91 \\
(0.210)\end{array}$ & $\begin{array}{c}4.27 \\
(0.200)\end{array}$ & $\begin{array}{c}5.63 \\
(0.320)\end{array}$ & $\begin{array}{c}9.03 \\
(0.905)\end{array}$ \\
\hline$\theta=1$ & $\begin{array}{c}3.95 \\
(0.192)\end{array}$ & $\begin{array}{c}4.14 \\
(0.197)\end{array}$ & $\begin{array}{c}5.40 \\
(0.357)\end{array}$ & $\begin{array}{c}9.35 \\
(1.486)\end{array}$ & $\begin{array}{c}3.23 \\
(0.236)\end{array}$ & $\begin{array}{c}3.64 \\
(0.235)\end{array}$ & $\begin{array}{c}5.14 \\
(0.438)\end{array}$ & $\begin{array}{c}9.79 \\
(1.866)\end{array}$ \\
\hline \multicolumn{9}{|c|}{ Percentage change in inequality from 1973 to 1981 after compensating for price changes } \\
\hline$\theta=0$ & $\begin{array}{l}9.28 \\
(1.349)\end{array}$ & $\begin{array}{c}6.91 \\
(0.186)\end{array}$ & $\begin{array}{l}7.50 \\
(0.276)\end{array}$ & $\begin{array}{l}10.25 \\
(0.621)\end{array}$ & $\begin{array}{c}8.80 \\
(1.475)\end{array}$ & $\begin{array}{c}6.57 \\
(0.186)\end{array}$ & $\begin{array}{l}7.20 \\
(0.272)\end{array}$ & $\begin{array}{c}9.80 \\
(0.569)\end{array}$ \\
\hline$\theta=0.5$ & $\begin{array}{l}11.05 \\
(1.070)\end{array}$ & $\begin{array}{c}9.07 \\
(0.254)\end{array}$ & $\begin{array}{c}9.78 \\
(0.419)\end{array}$ & $\begin{array}{l}13.02 \\
(0.956)\end{array}$ & $\begin{array}{l}10.46 \\
(1.169)\end{array}$ & $\begin{array}{c}8.62 \\
(0.254)\end{array}$ & $\begin{array}{c}9.38 \\
(0.415)\end{array}$ & $\begin{array}{l}12.51 \\
(0.926)\end{array}$ \\
\hline$\theta=1$ & $\begin{array}{l}10.79 \\
(0.654)\end{array}$ & $\begin{array}{c}9.14 \\
(0.291)\end{array}$ & $\begin{array}{c}9.94 \\
(0.510)\end{array}$ & $\begin{array}{l}14.02 \\
(1.272)\end{array}$ & $\begin{array}{l}10.21 \\
(0.709)\end{array}$ & $\begin{array}{c}8.68 \\
(0.291)\end{array}$ & $\begin{array}{c}9.55 \\
(0.506)\end{array}$ & $\begin{array}{l}13.66 \\
(1.252)\end{array}$ \\
\hline
\end{tabular}

Bootstrap standard errors in parentheses.

distributional effect. For $c=0$ and $\theta=0.5$, for instance, this decrease amounts to a 24,12 and $5 \%$ reduction of the term $\Delta P_{0}(0.5)$ in each of the three periods.

\section{Conclusions}

This paper investigates the conjecture raised by some critics of the Boskin commission's report that new products and goods influenced by quality effects are disproportionately consumed by the rich. Firstly, the results presented here confirm that the richer households indeed experience significantly more QCB. Secondly, the plutocratic gap (which has been positive in Spain 1973-1998) decreases substantially after the elimination of the QCB. Furthermore, the greater the overall QCB, the greater the reduction in the plutocratic gap. Thirdly, since prices have displayed an anti-rich behavior during 1973-1998 in Spain, the cost-of-living adjustment should be greater for richer households. As a result, after compensating for these price changes, equivalent household-expenditures inequality will increase. However, since the QCB affects predominantly the richer households, this distributional effect diminishes once the QCB is eliminated. 
We thank an anonymous referee for useful comments. Financial support from 'la Caixa' is gratefully acknowledged.

\section{References}

Boskin, M., Dulberger, E., Gordon, R., Griliches, Z., Jorgenson, D., 1996. Toward a More Accurate Measure of the Cost of Living, Final Report, Senate Finance Committee.

Buhmann, B., Rainwater, L., Schmauss, G., Smeeding, T., 1988. Equivalence scales, well-being, inequality and poverty: sensitivity estimates across ten countries using the Luxembourg income study database. Review of Income and Wealth $34,115-142$.

Cowell, F.A., Kuga, K., 1981. Additivity and the entropy concept: an axiomatic approach to inequality measurement. Journal of Economic Theory 25, 131-143.

Deaton, A., 1998. Getting prices right: what should be done? Journal of Economic Perspectives 12, 37- 46.

Madrick, J., 1997. The cost of living: a new myth. New York Review of Books, March 6;

Madrick, J., 1997. Cost of living: an exchange. New York Review of Books, June 26.

Moulton, B., Moses, K., 1997. Addressing the quality change issue in the consumer price index. Brookings Papers on Economic Activity 1, 305-349.

Prais, S., 1958. Whose cost of living? Review of Economics and Statistics 26, 126-134.

Izquierdo, M., Ley, E., Ruiz-Castillo, J., 2002. The Plutocratic Gap in the CPI: Evidence from Spain, forthcoming IMF Staff Papers.

Shorrocks, A.F., 1984. Inequality decomposition by population subgroups. Econometrica 52, 1369-1388. 